\title{
REFORMA DE SENTENÇA TERMINATIVA E JULGAMENTO IMEDIATO DO MÉRITO NO PROCESSO DO TRABALHO
}

\author{
Estêvão Mallet \\ Professor Associado do Departamento de \\ Direito do Trabalho da Faculdade de Direito \\ da Universidade de São Paulo
}

\begin{abstract}
Resumo:
O efeito devolutivo de recurso contra sentença terminativa (Lei n. 10.352) e o duplo grau de jurisdição em caso de reforma, além de antecedentes legislativos e Direito comparado são itens abordados pelo autor.
\end{abstract}

Abstract:

The returnable effect of the appeal against terminative sentence (Law n. 10,352) and the double jurisdiction grade in reformation cases, added to the legislatives antecedents and Comparated Law are the itens boarded by the author.

Unitermos: reforma de sentença terminativa; compatibilidade com processo trabalhista; Lei n. 10.352; efeito devolutivo da apelação

\section{Introdução.}

A reforma da legislação processual, iniciada em 1994, compreende medidas com diferentes graus de importância. Algumas envolvem correção de imperfeições pouco significativas, por vezes de caráter meramente terminológico, como é o caso, para mencionar apenas um exemplo recente, da nova redação dada ao art. 475, inciso II, do CPC. Substitui-se a equivocada alusão a improcedência da execução pela referência, tecnicamente mais correta, a procedência dos embargos à execução. Outras medidas, ao contrário, contêm avanços muito mais expressivos. Alteram diretrizes tradicionais, deixam de lado princípios sedimentados e abandonam postulados antes considerados intocáveis, tudo para permitir a prestação mais eficiente e eficaz da atividade jurisdicional. É o caso do $\S 3^{\circ}$, introduzido no art. 515 , do CPC, que, ao ampliar o efeito devolutivo da apelação, admite o imediato julgamento do mérito, em caso de reforma de sentença terminativa, nos seguintes termos: "nos casos de extinção do processo sem julgamento do mérito (art. 267), o tribunal pode julgar desde logo a lide, se a causa versar questão exclusivamente de direito e estiver em condições de imediato julgamento" 
Para interpretar adequadamente essa regra e bem compreender o seu significado é preciso ter em mente, em primeiro lugar, as limitações antes impostas ao eleito devolutivo da apelação.

2. Efcito devolutivo de recurso contra sentença terminativa antes da Lei n. 10.352.

De acordo com o regramento em vigor antes da Lei n. 10.352, a apelação, tal como o recurso ordinário do processo do trabalho - não há, entre um meio de impugnação e o outro, nesse ponto, diferença alguma -, tinha efeito devolutivo mais limitado. Quando interposta contra sentença terminativa, não permitia, caso reformada a decisão, o imediato julgamento do mérito do processo ${ }^{\prime} \mathrm{O}$ retorno dos autos ao juízo de primeiro grau, para exame do mérito, era de rigor, sob pena de nulidade da decisão, $\mathrm{cm}$ respeito, segundo se imaginava, ao princípio do duplo grau de jurisdição ${ }^{2}$

Na verdade, porém, a apontada limitação do cfeito devolutivo da apelação, antes da Lei n. 10.352, era fruto de mera opção legislativa. Não constituía desdobramento do princípio do devido processo legal ou mesmo da garantia de duplo grau de jurisdição. É o que cabe doravante demonstrar.

3. Duplo grau de jurisdição, devido processo legal e julgamento imediato do mérito em caso de reforma de sentença terminativa

O duplo grau de jurisdição, embora possa ser concebido com maior ou menor amplitude, variando, portanto, de um ordenamento jurídico para o outro ${ }^{3}$ normalmente não assegura pelo menos dois juízos sobre todas as questões discutidas

1. José Carlos Barbosa Moreira, Comentários ao Código de Processo Civil, Rio de Janeiro, Forense, 2000, vol. V, n. 238, p. 425.

2. Assim, expressamente, Antonio Carlos de Araújo Cintra, Sobre os limites objetivos da apelação civil, São Paulo, s. e. p., 1986, p. I02, e Humberto Theodoro Júnior, Curso de Direito processual civil, Rio de Janeiro, Forense, 2000 , v. I, n. 543, p. 505, nota 58. Em jurisprudência: "Apelação civil. Tuntum devolutum quantum apellattum. Art. 515 do CPC. Duplo grau de jurisdição. Extinto o processo, sem julganento do mérito, na instancia inferior, com base no art. 267, VI, do CPC, nāo é possível ao juízo de segunda instância, em grau de apelação, apreciar o mérito, julgando procedente a ação, sob pena de comprometer o duplo grau de jurisdição. Recurso extraordinário conhecido e provido."(STF - Ia T., RE n. V "hl\#hl” VI "h3\#h3" 103.588/SC, Rel. Min. Rafael Mayer, julg. em 03.12.84 in DJU de 19.12.84, p. $21.920)$ e "Apelação. Carência de ação reconhecida pela sentença. Impossibilidade do tribunal, apreciando recurso de apelação, julgar o mérito do pedido inicial. Violação do princípio do duplo grau de jurisdição e ofensa ao art. 515, par $1^{\circ}$, do CPC. Recurso extraordinírio parcialmente conhecido e provido."(STF $-1^{2}$ T., RE n. VI "h I\#h 1" V "J.3\#h.3" 84.467/SP, Rel. Min. Bilac Pinto, julg. em 19.10.76 in DJU de 19.11.76).

3. Enrico Redenti, Diritoo processuale civile, Varese, Giuffrì, 1985, 2, n. 161, p. 404. 
no processo. Garante simplesmente a possibilidade de a controvérsia, compreendid em sua integralidade, passar por duplo exame. Como escreve Mario Villani, consagração do duplo grau de jurisdição "non esige che ogni singola questione veng esaminata due volta: è la controversia nel suo complesso che deve pote passare...atraverso due gradi" 4 Torna-se isso muito claro quando se consideram c sistemas jurídicos que, embora acolhendo o princípio do duplo grau de jurisdição como ocorre no Direito francês -, permitem, com largueza, a apresentação, perante tribunal, de questões não examinadas no juízo recorridos Para essas questões nova não se oferece duplo exame.

Mesmo no direito brasileiro, que, nessa matéria, seguiu a linha do process austríaco, ${ }^{6}$ limitando sensivelmente a possibilidade de exame de questões novas $n$ juízo recursal, nunca se afastou completamente o jus novorum na apelação. Além d art. 517 , do CPC, a própria extensão conferida pelos $\$ \S 1^{\circ}$ e $2^{\circ}$, do art. 515 , também d $\mathrm{CPC}$, ao efeito devolutivo da apelação permite que certas questões fiquem sujeitas apenas um julgamento. Se a defesa assenta em dois diferentes fundamentos, pode dal se a rejeição do pedido por apenas um deles, sem exame do outro. Com o recurso $\mathrm{d}$ autor, ao tribunal transfere-se o exame de ambos os fundamentos, inclusive o daque] não apreciado em primeiro grau de jurisdição. E sobre esse fundamento, não examinad em primeiro grau, não haverá duplo juízo, mas apenas o juízo emitido pelo tribunal ${ }^{7}$

Assim entendido o duplo grau de jurisdição, percebe-se que possibilidade ou-não de exame imediato do mérito do processo, no caso de proviment

4. Appello (diritto processuale civile) em Enciclopedia del Diritto, Varese, Giuffrè, 1958, II, p. 719. No mesıno sentido, na jurisprudência trabalhista, colhe-se, eın acórdão proferido no ROAR n. 736.660, da SDI - II, do Tribunal Superior do Trabalho, relatado pelo Min. João Oreste Dalazen, a seguinte precisa afirınação:"... para a realização do princípio do duplo grau não se quer que o juízo "a quo" haja exaurido a matéria de mérito no julgamento da lide. Basta que haja julgado o(s) pedido(s)."(julg. em 05.03.00 in DJU de 12.04.02).

5. A conjugação do art. 564 com o art. 565, do Code de Procédure Civile, permite afirmar a ampl possibilidade de alteração da causa de pedir na apelação do direito francês, descle que não se altere pedido. É, ao que parece, a conclusão de Jean Vincent e Serge Guinchard (Procédure civile, Paris, Dallo: 1999, n. 1.431, p. 971) e de Gérard Cornu e Jean Foyer (Procédure civile, Paris, PUF, 1996, p. 61 l).

6. A propósito, Luiz Machado Guimarães, Efeito devolutivo da apelação in Estudos de direit processual civil, Rio de Janeiro, Editora Jurídica e Universitária, 1969, p. 216 e segs.

7. Figure-se um exemplo. Eın reclamação envolvendo pedido de pagamento de horas extras, oferec o reclamado defesa ein que alega: a) não-prestação de horas extras e b) exercício, pelo empregado, ( cargo de confiança, incompativel com a exigibilidade de horas extras (CLT, art. 62, inciso II). Julgad improcedente o pedido, com o acolhimento do primeiro fundamento da defesa, o recurso ordinári interposto pelo reclamante devolve ao tribunal o exame integral da lide, nos exatos termos do art. 515 , $\$$ $1^{\circ}$ e $2^{\circ}$, do CPC. Reconhecida a prestação de horas extras, ao tribunal cabe julgar se o empregado exerc ou-não cargo de confiança, embora sobre tal matéria não se tenha pronunciado o juízo de primeiro gra 
de recurso interposto contra sentença terminativa, constitui mera decorrência do efeito devolutivo da impugnação. Se esse efeito é mais limitado, por opção do legislador, o exame do mérito não pode ter lugar. Se, diversamente, atribui-se ao efeito devolutivo maior amplitude, pode-se desde logo julgar o mérito do processo. Em qualquer hipótese, contudo, não se elimina o princípio do duplo grau de jurisdição, que se acha preservado pela simples permissão do recurso.

De todo modo, o duplo grau de jurisdição não constitui - cumpre dizê-lo com clareza - decorrência necessária da garantia do devido processo legal, de modo que não está posto ao abrigo de qualquer limitação por parte do legislador ordinário. Prova-o a previsão, na Constituição brasileira - em que expressamente se acolhe a garantia do devido processo legal -, de causas julgadas em única instância (art. 102, incisos I e III). A questão é, aliás, absolutamente pacífica na jurisprudência da Suprema Corte norte-americana, em torno da qual se construiu, em grande medida, o conceito de devido processo legal. Em McKane v. Durston, por exemplo, registrou a Corte: " $A$ review by an appellate court of the final judgment in a criminal case, however grave the offense of which the accused is convicted, was not at common law, and is not now, a necessary element of due process of law. It is wholly within the discretion of the state to allow or not to allow such a review. A citation of authorities upon the point is unnecessary" ". Já em National Union v. Arnold reafirma-se a mesma idéia em matéria civil, consignando-se que "a statutory review...is not a requirement of due process"" Não discrepa a Jurisprudência do Supremo Tribunal Federal, como mostra decisão com a seguinte ementa: "Diante do disposto no inciso III do artigo 102 da Carta Política da República, no que revela cabível o extraordinário contra decisão de última ou única instância, o duplo grau de jurisdição, no âmbito da recorribilidade ordinária, não consubstancia garantia constitucional" 10

8. 153 U.S. 684.

9. 348 U.S. 37. Ainda em Reetz v. People of State of Michigan (188 U.S. 505) pode-se ler: “Neither is the right of appeal essential to due process of law... In civil cases a common rule is that the amount in comtroversy limits the entire litigation to one court..." Finalmente, em Luckenbach S.S. Co. V. United States (272 U.S. 533) encontra-se a seguinte assertiva: "The constitutional requirements are all satisfied if one opportunity is had for the trial of all parts of a case. Everything beyond that is matter of legislative discretion, not of constitutional right" Não é sem interesse notar que Thomas Cooley, ao indicar as características do due process of law, depois de se referir ao direito de ser previamente ouvido por um tribunal imparcial, com jurisdição adequada e aplicação de punição apenas depois do julgaınento, não menciona, em nenhum momento, o direito ao recurso (The general principles of constitucional law, New Jersey, The Lawbook Exchange, 2000, p. 224).

10. STF - 2a T., AgRg AJ n. 209.954-I/SP, Rel. Min. Marco Aurélio, julg. em 15.09.98 in D.J.U. de 4.12.98. Sempre no mesmo sentido, STF, 2a T., RHC 80.919-SP, Rel. Min. Nelson Jobim, julg. em 12.06.0I 
Em síntese, a possibilidade de julgamento imediato do mérito, em caso de reforma de sentença terminativa, não conflita, de modo algum, com a regra do duplo grau de jurisdição, ao menos nos termos em que ela é tradicionalmente concebida no Direito brasileiro, a qual, ademais, não exterioriza desdobramento necessário da garantia constitucional do devido processo legal.

4. Antecedentes legislativos e Direito comparado.

A nova previsão do $\S 3^{\circ}$, do art. 515 , do CPC, não é completa novidade no direito brasileiro e muito menos no comparado.

As Ordenações Filipinas, que tratavam com largueza o efeito devolutivo da apelação, estendendo-o a ambas as partes, inclusive à que não havia apelado" impunham, como regra, o imediato julgamento do mérito do processo em caso de reforma de sentença terminativa, repelindo a devolução dos autos ao juízo de primeiro grau para novo julgamento. Apenas excepcionalmente, havendo requerimento de ambas as partes, é que prevalecia solução diversa. Dispunha o Livro III, Título LXVIII, principio, das Ordenações Filipinas: "Quando alguma das partes appellar da sentença, que contra elle fôr dada... e depois que o feito fôr concluso, vejam-no os Julgadores, a que o conhecimento de tal appellação pertencer; e se fôr appellado da sentença interlocutória, e acharem que foi bem appellado, e que o appellante foi aggravado pelo Juiz, assio determinam, e não mandem tornar o feito ao Juiz, de que foi appellado, mas vão por elle em diante, e o determinem finalmente, como acharem por Direito, salvo, se o appellante e o appellado ambos requererem, que se torne o feito á terra perante o Juiz, de que foi appellado, porque então se tornará, e será assinado termo, a que o vão lá seguir" O Código de Processo da Bahia manteve tal diretriz, preceituando, no art. 1.290: "Tendo o juiz de primeira instância deixado, por qualquer motivo, de julgar a causa de meritis, a turma ou o juiz da appellação, si entender que isto não obsta que se conhę̧a do pedido, julgará a causa defintivamente"

No Direito comparado é paradigmática a solução vigente no Direito francês. $\mathrm{O}$ art. 568, do Code de Procédure Civile, preocupado com a rápida solução do

in Informativo STF 232, de 11 a 15 de junho de 2001, STF, la T., AgAICrim n. 248.761/RJ, Rel. Min. Ilımar Galvão, julg. em 11.04 .00 in DJU de 23.06.00, p. 10 e, ainda, STF, la T., HC-71.124/RJ, Rel. Min. Sepulveda Pertence, julg. em 28.06.94 in DJU de 23.09.94, p. 25.314. Isolada e minoritária, pois, a seguinte pronúncia: “...o princípio constitucional da ampla defesa...por si, pressupõe mais de um grau de jurisdição"(STJ - I² Sec., MS n. 4.83I-DF, Rel. Min. Demócrito Reinaldo in DJU de 16.06.97, p. 27.308i).

11. Alıneida e Sousa considera certíssima a máxima segundo a qual a apelação é comum a ambas as partes (Segundas linhas sobre o processo civil, Lisboa, Imprensa Nacional, 1855, parte II, nota 645, p. 385). 
litígio" determina: "Lorsque la cour d'appel est saisie d'un jugement qui a ordonné une mesure d'instruction, ou d'un jugement qui statuant sur une exception de procédure, a mis fin à l'instance, elle peut évoquer les points non jugés si elle estime de bonne justice de deonner à l'affaire une solotion définitive, après avoir ordonné elle-même, le cas échéant, une mesure d'instruction" No Cantão de Genebra a mesma possibilidade existe, mas depende de concordância das partes. O art. 311, da Lei de Procedimento Civil, de 1987, acha-se assim redigido: "Jugement sur incident. I. Si le jugement n'a tranché qu'un incident, la cour ne statue que sur cet incident; la décision du fond est renvoyée au juge de première instance. 2. Si toutes les parties le requièrent, la cour peut toutefois, en infirmant la décision du premier juge, par le même arrêt, prononcer sur le fond". Já no direito belga impõe-se ao juízo do recurso o imediato julgamento do mérito do litígio, ainda quando terminativa a decisão impugnada, impedindo-se mesmo o reenvio da causa ao juízo recorrido, salvo se confirmada determinação de realização de medida instrutória. O art. 1.068, do Code Judiciaire, tem, na redação francesa, o seguinte texto: "Tout appel d'un jugement définitif ou avant dire droit saisit du fond du litige le juge d'appel. Celui-ci ne renvoie la cause au premier juge que s'il confirme, même partiellement, une mesure d'instruction ordonnée par le jugement entrepris". O direito português mostra-se ainda mais avançado. Embora preveja recurso específico em caso de extinção do processo sem julgamento do mérito, correspondente ao agravo, reservando a apelação para os casos de extinção com julgamento do mérito, ${ }^{13}$ admite que, ao julgar o agravo, o tribunal desde logo resolva em definitivo o litígio. Preceitua o art. 753, n. 1, do Código de Processo Civil: "Sendo o agravo interposto de decisão final e tendo o juiz de $I^{a}$ instância deixado, por qualquer motivo, de conhecer do pedido, o tribunal, se julgar que o motivo não procede e que nenhum outro obsta a que se conheça do mérito da causa, conhecerá deste no mesmo acórdão em que revogar a decisão de $1^{\mathrm{a}}$ instância"

No Direito chileno merece referência o art. 208, do Código de Procedimiento Civil, assim redigido: "Podrá el tribunal de alzada fallar las cuestiones ventiladas en primera instancia y sobre las cuales no se haya pronunciado la sentencia apelada por ser incompatibles con lo resuelto en ella, sin que se requiera nuevo pronunciamiento del tribunal inferior"

Mesmo nos ordenamentos jurídicos da common law, a despeito das sensíveis diferenças que apresentam frente aos da civil law, encontra-se solução similar à do art.

12. Jean Vincent e Serge Guinchard, Procédure civile cit., n. 1447, p. 978.

13. É a regra geral, como exposto por João de Castro Mendes, que sublinha a existência de casos duvidosos e de situações excepcionais, envolvendo decisão de inérito suscetível de agravo (Direito processual civil, s. I. e., Edição AAFDL, 1989, IIIo vol., p. 87 e segs.). 
515, $\$ 3^{\circ}$, do CPC brasileiro. No art. 909, do Code of Civil Procedure do Estado norteamcricano da Califórnia, por exemplo, ao disciplinar o julgmento de apelação interposta cm causas não sujeitas a julgamento por juri, estatui o legislador: "The reviewing court may for the purpose of making the factual determinations or for any other purpose in the interests of justice, take additional evidence of or concerning facts occurring at any time prior to the decision of the appeal, and may give or direct the entry of any judgment or order and may make any further or other order as the case may require. This section shall be liberally construed to the end among others that, where feasible, causes may be finally disposed of by a single appeal and without further proceedings in the trial court except where in the interests of justice a new trial is required on some or all of the issues"

Como se vê, a solução consagrada no $\$ 3^{\circ}$, do art. 515 , encontra amplo respaldo nos mais diferentes diplomas legislativos.

\section{Fundamentos da regra.}

A possibilidade de imediato exame do mérito, em caso de acolhimento de recurso interposto contra sentença terminativa, acha-se respaldada na idéia de obıenção de maior rendimento na atividade jurisdicional.

É desejável, desde que não se comprometam as garantias fundamentais dos litigantes, que o processo ofereça o máximo possível de rendimento, com menor custo e dispêndio de tempo, em respeito ao princípio da economia processual. ${ }^{14}$

É igualmente desejável que, na medida do possível e respeitadas as condições pertinentes, leve o processo a decisão de mérito, resolvendo em definitivo o conflito existente entre os litigantes ${ }^{15}$ finalidade principal da atividade jurisdicional. ${ }^{16}$

14. Teve o Supremo Tribunal Federal ocasião de registrar: "Princípio da oralidade Economia processual. Tanto quanto possível, busca-se, com um mínimo de atuação judicante, a máxima eficácia das normas que compõem a ordem jurídica."(STF - Pleno, RCL-371/RR, Rel. Min. Marco Aurélio, julg. em 25.08.92, in DJU de 02.04.93, p. 5.61.3).

15. Interessante notar, a propósito, que o Revised Code do Estado norte-americano de Washington, em seu Tílulo 2.04.190, ao atribuir à Suprema Corte do Estado a prerrogativa de editar normas sobre pleading. practice, and procedure generally ("The supreme cout shall have the power to prescribe, from time to time, the forms of writs and all other process, the mode and manner of firming and filing proceedings and pleadings; of giving notice and serving writs and process of all kinds; of taking and obtaining evidence; of drawing up, entering and enrolling orders and judgments; and generally to regulate and prescribe by rule the forms for and the kind and character of the entive pleading. practice and procedure to be used in all suits, actions, appeals and proceedings of whatever nature by the supreme cout, superior courts, and district courts of the state"), impõe levem essas normas em conta o seguinte propósito: "In prescribing such rules the supreme court shall have regard to the simplification of the system of pleading, practice and procedure in said courts to promote the speedy determination of litigation on the merits". A preocupação com a promoção do rápido julgamento do mérito do litígio evidencia a relevância da nova regra do arı. $515, \$ 3^{\circ}$, do CPC brasileiro.

16. A propósito, Carlo A. Nicolleti, La conciliazine nel processo civile, Milano, Giufrè, 1963, n. 147 e segs. 
Assim, se a causa, quando de seu exame no juízo do recurso, diante do estado em que se encontra, já comporta julgamento de mérito, não há razão suficiente para que se devolvam os autos ao juízo de primeiro grau, a fim de que nova sentença seja proferida, tanto mais quando é muito provável que a nova decisão venha a ser impugnada, retornando o feito ao exame do tribunal. Haveria considerável gasto adicional de tempo e significativo acréscimo de custo para o aparelho judiciário, com ganho qualitativo pouco expressivo. Daí a preocupação do legislador, subjacente à regra do art. $515, \S 3^{\circ}$, do CPC, de evitar os "incômodos, despesas e demoras resultantes do vai-vem do processo", para utilizar as palavras de José Alberto dos Reis. ${ }^{17}$

É verdade que o julgamento do mérito apenas no juízo do recurso tem pelo menos um inconveniente: afasta a pronúncia sobre o fundo do litígio pelo órgão judiciário que colheu as provas, quebrando o vínculo que deve haver entre a atividade de produção da prova e a de julgamento da lide. Essa quebra é ainda mais indesejável, quando - como ocorre com freqüência no processo do trabalho - a análise das provas testemunhais é importante para a correta solução da lide. Isso porque os juízes que não ouviram as testemunhas depondo - ressalta François Gorphe, em estudo dedicado exatamente à valoração da prova testemunhal - "n'ont aucun moyen d'apprécier les témoignages"18 Nas palavras de Denti, "il vero giudizio di fatto è quello che si pone in rapporto di immediatezza com l'assunzione delle prove e discende da una participazione diretta del giudice alle attività istruttorie"19 Hazard e Taruffo ainda sublinham: "il giudice del dibattimento di primo grado si trova in una posizione in cui può meglio valutare la credibitlià dei testimoni"20

Mas o julgamento fundado em apreciação das provas testemunhais por quem não acompanhou a sua produção não é problema causado apenas pela regra do $\S$ $3^{\circ}$ do art. 515, do CPC, e nem seria eliminado com a sua revogação. Trata-se de dificuldade produzida pela amplitude do duplo grau de jurisdição no Direito brasileiro, que confere ao juízo do recurso a possibilidade de reexaminar o litígio em todos os

17. Código de Processo Civil anotado, Coimbra, Coimbra Editora, 1985, vol. VI, p. 184.

18. La critique du témoignage, Paris, Dalloz, 1927. p. 85.

19. Riforma o controriforma del processo civile? em Un progetto per la giastizia, Bologna, II Mulino, 1982, p. 288. Em termos quase idênticos, Mauro Cappelletti, Un idolo falso: el Codigo de $1942 \mathrm{em}$ Proceso, ideologías, sociedad, Buenos Aires, EJEA, 1974, p. 289.

20. La giustizia civile negli Stati Uniti, Bologna, II Mulino, 1993, p. 209. Veja-se ainda, no Inesıno sentido, a categórica advertência de Edoardo F. Ricci: "Se l'immediatezza-concentrazione è un valore del processo moderno, il secondo grado non è un processo degno di questo nome" (Doppio grado di giurisdizione (principio del), I) Dirinto processuale civile em Enciclopedia giuridica, Roma, 1989, v. 12, p. 8). 
seus aspectos ${ }^{21}$ Mesmo que, após a reforma de sentença terminativa, fosse proferido novo julgamento pelo órgão judiciário perante o qual se produziram as provas, especialmente a testemunhal, a interposição de recurso devolveria ao tribunal o reexame da causa, quebrando a imediação.

Em síntese, nos sistemas em que não há garantia efetiva de imediação como é o do Direito Processual brasileiro -, a regra do $\S 3^{\circ}$, do art. 515, do CPC, traz mais vantagens, em termos de economia de tempo e de custos, do que desvantagens. Sua adoção mostra-se, pois, plenamente justificável. Só deixaria de o ser se o recurso de apelação fosse sensivelmente limitado em seu efeito devolutivo, do ponto de vista da profundidade, para tornar soberana a decisão do juízo recorrido no tocante aos fatos em debate na causa.

\section{Compatibilidade com o processo do trabalho.}

A possibilidade de julgamento imediato do mérito, em caso de reforma de sentença terminativa, é perfeitamente compatível com o processo do trabalho.

O recurso ordinário do processo do trabalho, no tocante aos seus efeitos, não se distingue em nada da apelação regulada no direito comum. Trata-se exatamente do mesmo recurso, apenas com alteração nominal e com pequenas peculiaridades no tocante a certas condições de admissibilidade, tais como prazo e depósito recursal. A falta, no Direito brasileiro, de preceito como o art. $87^{\circ}$, do Código de Processo do Trabalho português, sujeitando expressamente os recursos do processo do trabalho ao regime de julgamento estabelecido pelo processo civil ${ }^{22}$, não tem relevo, suprida que se acha a lacuna pelo comando genérico do art. 769, da CLT. Aliás, tanto jurisprudência como doutrina já haviam realçado a aplicação das regras dos $\$ 1^{\circ}$ e $2^{\circ}$, do $\operatorname{art.~} 515$, ao recurso ordinário do processo do trabalho ${ }^{23}$ Não há razão para que se passe de modo diverso com o novo preceito adicionado a esse artigo.

21. Coıno escreve Pedro Batista Martins, o duplo grau de jurisdição "importa o sacrifício de um dos princípios cardeais do sistema oral: o da imediaçāo"(Recursos e processos da competência originária dos tribunais, Rio de Janeiro, Forense, 1957, n. 109, p. 150).

22. O art. $87^{\circ}$, do Código de Processo do Trabalho português, com a redação dada pelo Decreto-Lei n. 480/99, tem o seguinte teor: "O regime de julgamento dos recursos é o que resulta, com as necessárias adaptaçōes, das disposições do Código de Processo Civil que regulamentam o julgamento do recurso de agravo, quer interposto na $I^{2}$ instância, quer na $2^{\mathrm{a}}$ instância, conforme os casos".

23. Em Jurisprudência: "Recurso - Devolutividade - Amplitude. Se o reclamado em sua defesa articulou mais de un fundamento mas apenas um deles foi acolhido pela sentença de primeiro grau, o recurso ordinário interposto devolverá ao Tribunal o conhecimento dos demais fundamentos da defesa, ainda que não apreciados pela Junta de Conciliação e Julgamento. Inteligência do art. 515 do CPC. Recurso conhecido e provido."(TST - SBDII - ERR n. 208.313/95-I, Rel. Min. Vantuil Abdala in DJU de 21.05.99, p. 87). Em doutrina, cf. Estêvão Mallet, Procedimento sumaríssimo trabalhista, São Paulo, LTr, 2002, n. 38, p. 100/101. 
Ademais, a finalidade perseguida pela norma do $\S 3^{\circ}$. do art. 515 , do $\mathrm{CPC}$, encontra-se afinada com o art. 765, da CLT, que sublinha a importância do rápido andamento das causas trabalhistas.

Não há, pois, como pôr em dúvida a possibilidade de aplicação do $\$ 3^{\circ}$, do art. 515, do CPC, no processo do trabalho ${ }^{24}$

7. Pressupostos para o julgamento imediato do mérito $\mathrm{cm}$ caso de reforma de sentença terminativa.

No Direito brasileiro o exame do mérito do litígio, em caso de reforma de sentença terminativa, depende, consoante o texto do $\$ 3^{\circ}$ do art. 515, do CPC, da natureza da questão em debate, que deve ser, segundo a fórmula legal, "exclusivamente de direito", e da possibilidade de se dar, desde logo, o seu julgamento.

Logo de início percebe-se o equívoco do legislador $\mathrm{cm}$ referir-se a questão cxclusivamente de direito. Na verdade, questão alguma é exclusivamente de dircito porque - como lembra Lopes da Costa - a discussão sobre a norma a aplicar "não pode ser de modo absoluto separada da questão de fato. É do fato que nasce o direito. Ex facto ius oritur" 25

Realmente, pretender separar, de modo rígido, fato e direito não sc compreende. A própria análise dos fatos não é simplesmente atividade voltada à consideração da realidade. A discriminação dos fatos a serem considerados supõe já certo enquadramento jurídico da situação, porque os fatos são sempre constatados tendo cm vista "um determinado sentido jurídico" ${ }^{26}$ Daí dizer Karl Larenz que todas as situações de fato a apreciar juridicamente "não representam uma pura enumeração de fatos, mas são o resultado de uma certa escolha...em atenção ao que nisso pode ser juridicamente relevante" ${ }^{27}$ Os fatos são muito variados e nem todos os aspectos da situaç̧̃̃o ocorrida revestem-se de relevância jurídica. Assim, é preciso separar, entre os

24. Em Jurisprudência, aplicando já a nova regra no processo do trabalho: "A lei processual em vigor pôs fim ao formalismo inútil da chamada supressão de instância. Sc o juiz declarar extinto o processo nos termos do art. 267 do CPC, pode o Tribunal afastar o motivo e decidir a lide..."(TRT - 2a Reg., $9^{\mathrm{a}}$ T., RO n. 20010377039, Ac. n. 20020198595, Rel. Juiz Luiz Edgar Ferraz de Oliveira, julg. em 01.04 .02 in Revista Nacional de Direito do Trabalho, n. 50, junho de 2002, p. 163).

25. Direito processual civil, Rio de Janeiro, Forense, 1959, v. III, n. 4I9, p. 409.

26. Jan Schapp, Problemas fundamentais da metodologia jurídica, Porto Alegre, Fabris Editor, 198. p. 40 .

27. Metodologia da ciência do direito, Lisboa, Fundação Calouste Gulbenkian, 1989, p. 335. 
diversos acontecimentos, aqueles efetivamente importantes para a análise jurídica do problema. Mas a própria delimitação dos acontecimentos relevantes supõe já possível enquadramento jurídico da situação, porque conforme scja uma ou outra a norma aplicável, variam os fatos dignos de consideração. Em conseqüência, a definição dos fatos e a determinação da norma de regência não são momentos distintos e estanques do processo de formulação da sentença. Muito ao contrário, "a constatação dos fatos está inserida na apreciação jurídica", consoante adverte Schapp ${ }^{28}$ o que transforma a atividade decisória em verdadeiro "círculo hermenêutico"29, para utilizar a expressiva lórmula cunhada por Larenz.

Em perfeita sintonia com esse entendimento, Iembra Mandrioli ser impossível conceber como duas operações absolutamente distintas os juízos sobre os fatos e sobre o direito, "perché il gitudizio di diritto presuppone, nella sua stessa impostazione...un primo orientamento che non può esser dato che dai fatti, mentre il giudizio di fatto presuppone la cernita e la messa a fuoco degli elementi rilevanti, la quale presuppone a sua volta il riferimento alla portata della norma"30 Aliás, nem mesmo no juízo abstrato de constitucionalidade das normas - em que presumivelmente menos importância poderia ter a realidade concreta - a separação entre fatos e direito mostra-se cabível, aludindo a doutrina à necessidade de "investigação integrada de elementos fáticos e jurídicos" ${ }^{31}$ E tanto é verdade que a Lei n. 9.868, ao regular o procedimento para julgamento da ação direta de inconstitucionalidade c da ação declaratória de constitucionalidade, reconheceu a importância que os fatos podem ter no exame da controvérsia, admitindo sejam solicitados pareceres ou ouvidos especialistas. ${ }^{32}$

Em conseqüência, superada a pretendida separação rígida entre questão de fato e questão de direito, a inadequada fórmula do $\$ 3^{\circ}$, do art. 515, do CPC, passa a dirigir-se às situações em que já há nos autos elementos suficientes para resolução da controvérsia sobre os fatos relevantes no processo, tornando desnecessárias novas diligências. É, aliás, a mesma solução estabelecida para hipótese assemelhada - embora

28. Problemas fundamentais da metodologia jurídica cit., p. 40.

29. Metodologia da ciência do direito cit., p. 337.

30. Corso di diritto processunale civile, Torino, Giappichelli, 1993, I, \$\$17, p. 81 .

31. Gilmar Ferreira Mendes, Controle de constitucionalidade: hermenêutica constitucional e revisão de fatos e prognoses legislativos pelo órgão judicial in Jurisdiçāo constitucional, São Paulo, Saraiva, 1999, p. 356.

32. Arts. $9^{\circ}, \S 1^{\circ}$ e $20, \S 1^{\circ}$ 
não idêntica, sublinhe-se -, consoante previsão do parágrafo único, do art. 740, do CPC: "Não se realizará audiência, se os embargos versem sobre matéria de direito ou, sendo de direito e de fato, a prova for exclusivamente documental, caso em que o juiz proferirá a sentença no prazo de 10 (dez) dias" Em ambos os casos, a desnecessidade de novas diligências impõe o pronto julgamento da causa.

Definido o correto significado da imprópria referência a "questão cxclusivamente de direito", cabe agora apurar se as duas condições mencionadas no $\$$ $3^{\circ}$, do art. 515, do CPC, antes indicadas, são aditivas. A esse propósito cumpre ter em vista que a utilização da partícula "e" nem sempre traduz idéia de adição, ao contrário do que a alguns pareceu. ${ }^{33}$ Por vezes serve apenas como "designativa de ordem", como sublinhou Correa Telles, nas notas que apôs à Teoria da interpretação das leis de Domat, demonstrando sua afirmação com o seguinte exemplo: "se me perguntarem...quaes são os herdeiros necessários, e eu responder, que são os descendentes e ascendentes, nem por isso quero dizer, que os ascendentes succedem junctamente com descendentes" 34 Outras vezes a partícula tem significado alternativo. É o que ocorre quando, para a pergunta sobre os caminhos para se chegar a determinado local, indicase que se pode adotar o caminho A e o caminho $\mathrm{B}^{35}$ Tome-se exemplo ainda mais próximo da questão em debate. Refere-se o art. 475, inciso I, do CPC, ao tratar do reexame necessário, à sentença "proferida contra a União, o Estado, o Distrito Federal, o Município, e as respectivas autarquias e fundações de direito público". A despeito do duplo emprego do "e" a ninguém ocorrerá dizer que está sujeita ao reexame necessário apenas a sentença simultaneamente contrária a todas as pessoas mencionadas. A função alternativa - e não-aditiva - das partículas é, no caso, inegável.

Pois bem, se, como visto, o "e" não indica necessariamente adição, não laria sentido algum que tivesse esse significado no $\S 3^{\circ}$, do art, 515, do CPC. Qual o motivo para afastar o exame imediato do mérito do litígio quando semelhante resultado se pode logo obter, embora não seja "exclusivamente de direito" a questão? Buscou-

33. César Marcos Klouri, Comentários às alterações do Código de Processo Civil in Revista do Instituto dos Advogados de São Paulo, São Paulo, RT, n. 9, janeiro-junho de 2002, p. 201. 431 .

34. Auxiliar jurídico - Apêndice às Ordenações Filipinas, Lisboa, Calouste Gulbenkian, 1985, v. I, p.

35. Interessante notar que por vezes é o contrário o que se verifica. Adquire a particula "ou" significado aditivo e nāo-alternativo. Exemplo expressivo encontra-se no caput, do art. 286, do CPC. Sobre essa hipótese, cf. José Carlos Barbosa Moreira, O novo processo civil brasileiro, Rio de Janeiro, Forense, 1993, p. I3, e José Joaquim Calmon de Passos, Comentários ao Código de Processo Civil, Rio de Janciro, Forense, 1989, v. 3, p. 214. 
se, com a dispensa de retorno dos autos ao juízo de primeiro grau, permitir a prestação mais eficiente, eficaz e rápida da atividade jurisdicional, ideal a ser prestigiado e favorecido. Logo, não há razão alguma para limitar os casos em que a providência tem lugar. Daí porque não é preciso estarem presentes simultaneamente as duas condições mencionadas no art. $515, \S 3^{\circ}$, do CPC, para que se julgue o mérito logo após a reforma da sentença terminativa.

Em conseqüência, mesmo havendo controvérsia sobre direito e também sobre fatos, se já foram realizadas todas as diligências pertinentes ao esclarecimento desses fatos, após larga instrução processual, sem, todavia, decisão de mérito pronunciando-se, por exemplo, a carência de ação, o que sabidamente pode ocorrer a qualquer tempo (CPC, art. 267, $\left.\S 3^{\circ}\right)^{36}-$, o acórdão que reformar a sentença poderá desde logo reconhecer a procedência do pedido. Diversamente, se, pelo acolhimento de preliminar de inépcia, suscitada em defesa, o julgamento terminativo ocorreu sem que as provas tenham sido produzidas, afastada a inépcia, o julgamento do mérito não pode se dar de imediato. Em síntese, teria sido muito mais simples se houvesse o legislador brasileiro deixado claro, com melhor técnica, que o imediato julgamento do mérito depende apenas da inexistência de qualquer obstáculo, seja por não ter havido controvérsia sobre os fatos no juízo recorrido, seja por já haverem sido produzidas todas as provas necessárias ao deslinde da controvérsia.

8. Natureza da atribuição de julgamento imediato do mérito.

Presentes os pressupostos antes analisados, o julgamento imediato do mérito não constitui mera faculdade conferida ao juízo do recurso. Trata-se, ao

36. Cf., sobre o tema, Liebman, Manual de direito processual civil, Sāo Paulo, Forense, 1985, vol. I, n. 74, p. 1.54. Em jurisprudência: "Acerca dos pressupostos processuais e das condições da ação, não há preclusão para o juiz, a queın é lícito, em qualquer tempo e grau da jurisdição ordinária, reexaminá-los, não estando exaurido o seu ofício na causa."(STJ - 4a T., Resp n. 18.71 I/SP, Rel. Min. Barros Monteiro, julg. de 31.05.93 in DJU de 30.08.93, p. 17.296.); "O tribunal da apelação, ainda que decidido o mérito na sentença, poderá conhecer de ofício da matéria concernente aos pressupostos processuais e às condições da ação. Nas instâncias ordinárias não há preclusão para o órgão julgador enquanto não acabar o seu ofício jurisdicional na causa pela prolação da decisão final."(STJ - 4a T., AGREsp n. 192.199/RS, Rel. Min. Sálvio de Figueiredo Teixeira, julg. em 10.08.99 in DJU de 20.09.99, p. 66). De modo ainda mais abrangente, adınitindo até mesmo o reexame de decisão de saneamento, para declarar carência de ação antes afastada: "Após declarar saneado o processo, não fica o juiz impedido de declarar a ilegitimidade da parte. A preclusão é sanção imposta à parte e não ao juiz, que pode examinar os pressupostos processuais e as condições da ação desde a petição inicial até o julgamento definitivo da lide."(STJ - Ia T., Resp n. 199.47I/RJ, Rel. Min. Garcia Vieira, julg. em 04.05.99, in DJU de 21.06.99, p. 87). No sentido do último julgado, etn doutrina, Ovídio Batista da Silva, Curso de processo civil, São Paulo, RT, 1998, vol. 1, p. 21 I e José Rogério Cruz e Tucci, Sobre a eficácia preclusiva da decisão declaratória de saneamento in Revista dos Tribunais, v. 640, passim, especialmente p. 23. 
contrário, de verdadeiro dever. ${ }^{37} \mathrm{O}$ fato de haver o legislador disposto que o tribunal "pode julgar desde logo a lide" não o impondo claramente, não é de modo algum determinante.

Em primeiro lugar, é sabido que muitas vezes a expressão utilizada pelo legislador, reconhecidas as deficiências e as limitações da interpretação gramatical, não constitui o argumento decisivo no campo da hermenêutica jurídica. ${ }^{38}$ Poder-se-ia dizer, repetindo Celso: "conhecer as leis não é ater-se a suas palavras, mas compreender sua força e efeitos" "39 Mais tarde Emilio Betti afirmaria ser a superação da interpretação "alla lettera della legge" a principal exigência imposta ao verdadeiro intérprete do Direito ${ }^{40}$, até porque o correto sentido de qualquer declaração, não apenas das declarações jurídicas, depende sempre "de pressupostos mais complexos que o puro sentido literal" 4 . Não custa sublinhar o que teve a Suprema Corte norte-americana ocasião de assentar, em United States v. American Trucking Ass'ns, de 1940, ao expor as limitações da interpretação meramente literal, que por ela nunca foi considerada decisiva e determinante: "There is, of course, no more persuasive evidence of the purpose of a statute than the words by which the legislature undertook to give expression to its wishes. Often these words are sufficient in and of themselves to determine the purpose of the legislation. In such cases we have followed their plain meaning. When that meaning has led to absurd or futile results, however, this Court has looked beyond the words to the purpose of the act. Frequently, however, even when the plain meaning did not produce absurd results but merely an unreasonable one plainly at variance with the policy of the legislation as a whole' this Court has followed that purpose,

37. No mesmo sentido, de modo hesitante, porém, e sem indicação de fundamentos para a conclusão, Luiz Rodrigues Wambier e Teresa Arruda Alvim Wambier, Breves Comentários à $2^{\mathbf{a}}$ Fase da Reforma do Código de Processo Civil, São Paulo, RT, 2002, p. 142.

38. Cf., dispensando outras referências, Francesco Ferrara, Tratıato di diritto civile italiano, Roma, Athenaeum, 1921, t. I, p. 214. Na jurisprudência vale a alusão ao seguinte julgado do Superior Tribunal de Justiça: "Muitas vezes a interpretação literal contraria profundamente o espírito da lei"(STJ la T., REsp. n. 231.313-RS, Rel. Min. Humberto Gomes de Barros, julg. em 22.08.00 in Revista do Superior Tribunal de Justiça, vol. 140, p. 143/144).

39. Digesto, I, 111, 17.

40. Interpretazione della legge e degli atti giuridici, Milano, Giuffrè, 1949, 179/180.

41. Philipp Heck, Interpretação da lei e jurisprudência Jos interesses, São Paulo, Saraiva, 1948, p. 53. Em Helvering v. New York Trust Co., de 1934, assinalou a Suprema Corte norte-americana: " $a$ thing" which is within the intention of the makers of a statute is as much within the statute as if it were within the letter; and a thing which is within the letter of a statute, is not within the statute, unless. it is within the intention of the makers" (292 U.S. 4.55). 
rather than the literal words" ${ }^{\prime 42}$ Certamente não será preciso insistir ainda mais no ponto.

Não bastasse o já exposto, freqüentemente exprime o legislador verdadeira obrigação imposta ao juiz por meio da alusão a algo que pode ele fazer ${ }^{43.3}$ Un bom exemplo encontra-se no art. 273, do CPC, que igualmente alude à possibilidade de o juiz antecipar a tutela pedida, já havendo a doutrina sublinhado que o provimento tcm de ser concedido, tanto que presentes os seus pressupostos ${ }^{44}$ Por isso mesmo, quando se está diante de verdadeira faculdade, a fórmula legal é clara e induvidosa, como ocorre, por exemplo, no direito francês, em que o julgamento imediato do mérito lica condicionado a que o tribunal considere "de bomne justice de donner à l'affaire une solution définitive", nos termos do art. 568, do Code de Procédure Civile, anteriormente mencionado ${ }^{45}$

Cabe lembrar ainda, em tercciro lugar, que a obtenção do maior rendimento com a atividade processual, idéia que, em correspondência com o princípio da economia processual, inspira a norma do $\S 3^{\circ}$, do art. 515 , do CPC, ${ }^{46}$ não pode ficar na dependência da vontade do julgador. Constitui, pelo contrário, objetivo a ser perseguido permanentemente, sem prejuízo das garantias conferidas aos litigantes. E tanto é assim que o Superior Tribunal de Justiça já realçou ser o julgamento antecipado da lide providência de caráter obrigatório e não facultativo. ${ }^{47}$

42. 310 U.S. 534. Também em Helvering v. Morgan's Inc., de 1934, a Corte sublinhou a mesma proposição, aduzindo, em material tributária: "...the true meaning of a single section of a statute in a setting as complex as that of the revenue acts, however precise its language, cannot be ascertained if it be comsidered apart from related sections, or if the mind be isolated from the history of the income tax legislation of which it is an integral part"(293 U.S. I2I).

43. Sobre o tema, amplamente, Carlos Maximiliano, Hermenêutica e aplicação do direito, Rio de Janeiro, Forense, 1991, n. 331 e ss., p. 270 e ss.

44. No processo civil, cf. José Carlos Barbosa Moreira, A antecipação da tutela jurisdicional na refonna do Código de Processo Civil in Revista de Processo, São Paulo, RT, 1996, n. 81, p. 208, e, no processo do trabalho, Estêvão Mallet, Antecipação da tutela no processo do trabalho, São Paulo, LTr, 1999, p. 94.

45. Compreende-se, ante tal fórmula, considere a doutrina francesa o julgamento imediato do mérito “une simple faculté, nullement une obligation"(Jean Vincent e Serge Guinchard, Procédure civile cit., n. 144.5, p. 977).

46. Antes, item 5.

47. O acórdão temn a seguinte eınenta: "Presentes as condições que ensejaın o julgamento antecipado da causa, é dever do juiz, e não mera faculdade, assim proceder"(STJ - 42 T., REsp n. 2.832-RJ, Rel. Min. Sálvio de Figueiredo in DJU de 17.09.90, p. 9.513). Ainda na mesina linha: "Cerceamento de defesa. Dispensa de testemunha. Não configuração...não configura cerceamento de defesa a dispensa de testemunha quando o julgador, sentindo-se convencido com a prova colhida, inclusive testemunhal, entender desnecessária a oitiva das demais testemunhas arroladas face a inexistência de controvérsia acerca do fato probante"(STJ - 3a T., RESP n. 40.2 I2/BA, Rel. Min. Cláudio Santos in DJU de 02.05.94, p. 10.008). 
Por fim, no processo do trabalho é ainda mais evidente o caráter imperativo do julgamento imediato do mérito, quando presentes os pressupostos mencionados no $\S 3^{\circ}$, do art. 515 , diante da obrigação imposta ao juízo pelo art. 765 , da CLT.

9. Julgamento imediato do mérito e conduta do recorrente.

Do que acaba de ser dito no item anterior tira-se que o julgamento imediato do mérito, em caso de reforma de sentença terminativa, não depende de requerimento do recorrente. Não cabe argumentar, para justificar solução diversa, com o caput, do art. $515,^{4 k}$ porque $o \S 3^{\circ}$ constitui exceção à primeira norma. Tampouco importa o desejo da parte de, com o retorno dos autos ao juízo recorrido, produzir provas adicionais. ${ }^{49}$ De duas, uma: ou as provas que a parte pretende produzir são pertinentes, ou não. Sendo pertinentes, não cabe aplicação do $\S 3^{\circ}$, do art. 515 , porque não se encontram presentes as condições para o julgamento imediato do mérito no juízo do recurso. ${ }^{50}$ Se são impertinentes as provas, não serão produzidas nem mesmo em primeiro grau de jurisdição (CPC, art. 130, parte final), por mais que o deseje a parte. ${ }^{51} \mathrm{~A}$ vontade do litigante é, no particular, irrelevante. O que importa é a necessidade objetiva da prova. Logo, se entende o juízo do recurso, diante do estado do processo, desnecessárias novas provas, deverá de imediato julgar o mérito do litígio. Fazendo-o não cerceará a defesa de quem quer que seja $^{{ }^{52}}$. Claro está, de todo modo, que, equivocado o seu entendimento - porque era necessária a prova indeferida -, se configura error in procedendo, tornando-se a decisão suscetível de anulação.

Desnecessário, como visto, requerimento para que se aplique o $\S 3^{\circ}$, do art. 515, do CPC, não há se falar em oposição do recorrente ou mesmo do recorrido ao

48. O argumento encontra-se em Cândido Rangel Dinamarco, Os efeitos dos recursos in Aspectos polêmicos e atuais dos recursos cíveis, São Paulo, RT, 2002, p. 38.

49. Novamente Cândido Rangel Dinamarco, Os efeitos dos recursos cit., p. 39.

50. Antes, item 7.

51. “Ao julgador incumbe indeferir as diligências inúteis ou meramente protelatórias, na esteira do éntendimento do art. 130 do Código de rito" ( $2^{\circ}$ Trib. Alçada Civil - SP, 11 a Câm., Ap. n. 593.076-00/0, Rel. Juiz Mendes Gomes in Boletim ADCOAS n. 8192095). Invocando expressamente a aplicação subsidiária do art. 130, do CPC, no processo do trabalho, cf. TRT - $12^{\mathrm{a}}$ Reg., $3^{\mathrm{a}}$ T., Ac. $\mathrm{n}^{\mathrm{o}}$ 5365/98, Rel ${ }^{\mathrm{a}}$ Juíza Lourdes Dreyer in DJSC de 22.06.98, p. 74.

52. Eın termos gerais, veja-se, a propósito, o seguinte aresto: “Não pratica cerceaınento de defesa a decisão que julga antecipadaınente a lide, afirmando ser dispensável a realização de perícia com vistas a constituir prova sobre fato cuja comprovação documental cabia à concordatária, que não cuidou de fazêla oportunamente"(STJ - $4^{\mathrm{a}}$ T. Ag n. 43.975-5-RS, Rel. Min. Sálvio de Figueiredo in DJU de 23.05.94, p. 12.616). 
imediato julgamento do mérito. A conclusão do processo não fica sujeita à iniciativa das partes (CPC, art. 262). Se o litígio já se encontra em condições de julgamento, não podem as partes se opor a que isso ocorra, nem lhes cabe produzir diligências inúteis ou protelatórias (CPC, art. 130, parte final).

\section{0. Âmbito de incidência.}

O julgamento imediato do mérito, no campo trabalhista, tem cabimento, normalmente, no julgamento do recurso ordinário. Hipótese mais freqüente é a de cumulação objetiva de ações. Pleiteando o reclamante, por exemplo, o pagamento de horas extras e equiparação salarial, realizada a instrução em torno de ambos os pedidos, o segundo é, ao ensejo do julgamento, considerado inepto. Afastada, no julgamento do recurso ordinário, a inépcia, segue-se o exame do mérito do pedido de equiparação salarial.

Pode-se aplicar o $\S 3^{\circ}$, do art. 515 , mesmo sem que haja cumulação objetiva de ações. Ajuizada a reclamação apenas para o pagamento de horas extras, sem a prévia tentativa de conciliação (CLT, art. 625-D, caput), equivocadamente se pronuncia, após a completa instrução do feito, a carência de ação ${ }^{53}$. Sobrevindo reforma da decisão, com o julgamento do recurso, prossegue-se desde logo no exame do mérito do litígio. $\mathrm{O}$ mesmo se pode dizer no caso de incompetência absoluta da Justiça do Trabalho, afirmada após a produção de todas as provas requeridas pelas partes. Afastando o Tribunal a incompetência, julgará de imediato o mérito.

Também na hipótese de reconvenção pode haver aplicação do $\S 3^{\circ}$, do art. 515, do CPC. Repelida a reconvenção, depois de regularmente contestada, por

53. A solução é equivocada porque, como se procurou mostrar em outra oportunidade (Primeiras linhas sobre as comissões de conciliação in Revista LTr. São Paulo, v. 64-04, p. 444), a falta de prévia tentativa de conciliação não obsta o julgamento do mérito do pedido. Nesse sentido: "Comissão de conciliação prévia - Submeter a controvérsia à Comissāo de Conciliaçāo Prévia não é um dos pressupostos da af̧ão. É uma faculdade da parte. Raciocinar em sentido contrário seria obstaculizar o exercício da cidadania constitucionalmente previsto, e que assegura a todos o acesso ao Poder Jurisdicional para dirimir questōes que envolvem violação a direito, a uma norma de hierarquia inferior, no caso a Lei $n$. 9958/2000." (TRT 2 Reg., $4^{2}$ T., RORS n⿳0 07873200290202009, Rel. Juiz Sergio Winnik, julg. em 09.04.02 in DJ de 19.04.02) e "Comissão de Conciliação Prévia. Artigo 625-D, da CLT. Não há cominação para o não comparecimento à comissão de conciliação prévia, razão pela qual, constituindo uma faculdade (e não uma obrigação), não impede o ajuizamento da ação na Justiça do Trabalho."(TRT $-2^{\mathbf{a}}$ Reg., $6^{\mathrm{a}}$ T., RO n. 20010369320, Rel. Juíza Rita Maria Silvestre, julg. em 16.04.02, in DJ de 03.05.02). Existem, porém, julgados em sentido contrário. Por exemplo: “...qualquer demanda de natureza trabalhista, inclusive

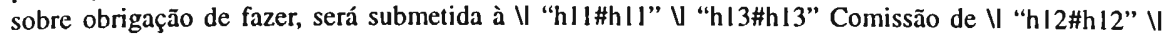
"h14\#h14" Conciliação Prévia se, na localidade da prestação de serviços, ela houver sido instituída no âmbito da empresa ou do sindicato (art. 625-D), sob pena de V "hI3\#hl3" V "hl5\#hl5" extinção do feito."(TRT - 3 Reg., 2 T., RO n. 12.121/2001, Rel. Juíza Alice Monteiro de Barros, julg. eın 09.10.01 in DJMG de 17.10.01, p. 21). 
considerar-se ausente o pressuposto da conexão, mencionado no art. 315 , caput, do $\mathrm{CPC}$, se a instrução realizada na ação principal permite o esclarecimento da matéria suscitada na reconvenção, o tribunal, reformando a sentença de extinção, examinará logo o pedido deduzido pelo reclamado.

Se o recurso ordinário é interposto em processo de competência originária do Tribunal Regional, como em dissídio coletivo, ação rescisória ou mesmo mandado de segurança, a regra do $\S 3^{\circ}$ : do art. 515, do CPC, satisfeitos os seus pressupostos específicos, tem plena aplicação. Daí porque, extinto o dissídio coletivo sem exame do mérito, por considerar-se que não se esgotou a tentativa de negociação, a reforma da decisão devolve ao Tribunal Superior do Trabalho, não havendo necessidade de novas provas, o exame do mérito do litígio. Julga-se logo o pedido, sem necessidade de baixa dos autos ao Tribunal Regional.

Em procedimento sumaríssimo, incide igualmente a permissão de julgamento imediato do mérito, em caso de reforma de sentença terminativa. A especialidade desse procedimento não é incompatível com a norma do art. $515, \S 3^{\circ}$, do CPC.

O mesmo não se verifica, todavia, no procedimento sumário da Lei n. 5.584, não derrogado pela Lei n. $9.957 .{ }^{54}$ É que nesse último procedimento não se admite a interposição de recurso ordinário, mas apenas de recurso extraordinário, em caso de ofensa à Constituição ${ }^{55}$

Uma vez que o exame imediato do mérito, em caso de reforma de sentença terminativa, não contraria o duplo grau de jurisdição, como se procurou mostrar acima, ${ }^{56}$

54. Estêvão Mallet, Procedimento sumaríssimo trabalhista cit., pp. $21 / 22$.

55. Sobre a questão, Estêvão Mallet, Do recurso de revista no processo do trabalho, São Paulo, LTr, 1995, n. 6.1, pp. 43/44. Em jurisprudência: "Recurso extraordinário. Causas de alçada. Decisão, emn instância única, de primeiro grau, versando matéria constitucional. Dela cabe recurso extraordinário ao Supremo Tribunal Federal (...) e não recurso a órgão judiciário de segundo grau"(STF - $2^{\mathrm{a}}$ T., Proc. RE n. 140.1699, Rel. Min. Neri da Silveira in DJU n. 53, de 19.3.93, p. 4.283) e "A existência de contencioso constitucional, a ser dirimido pelo Supremo Tribunal Federal, viabiliza a interposição de recurso

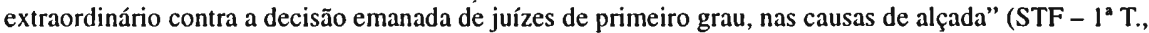
RE n. 182.995-8, Rel. Min. Ilmar Galvão, julg. em 08.11.94 in DJU n. 164, de 25.08.95, p. 26.078). Sempre no mesmo sentido, STF - $1^{\text {a }}$ T., Proc. RE n. 136.149-2, Rel. Min. Moreira Alves in DJU n. 213, de 06.11.92, p. 20.107, e STF - Plenário, REC n. 510-1, Rel. Min. Ilmar Galvão, julg. em 23.02.95 in DJU n. 85, de 05.05.95, p. 11.904. Sem razão, portanto, o seguinte acórdão do Tribunal Superior do Trabalho: "Cabe recurso ordinário das sentenças proferidas nos dissídios de alçada que versem matéria constitucional" (TST - 4 T., Proc. RR n. 115.591/94, Rel. Juiz convocado Rider Nogueira de Brito in DJU n. 238, de 16.I2.94, p. 35.138).

56. Antes, item 3. 
a regra do $\S 3^{\circ}$, do art. 515 , do $\mathrm{CPC}$, abrange ainda o recurso ordinário ex officio, previsto no art. $1^{\circ}$ inciso V, do Decreto-Lei n. 779.57

A nova disciplina estabelecida pela Lei n. 9.756 estende a aplicação do $\$ 3^{\circ}$ do art. 515, do CPC até mesmo ao julgamento proferido após o provimento de agravo de instrumento. Denegado recurso ordinário interposto contra sentença terminativa, o provimento do agravo, nos termos do art. $897, \S 7^{\circ}$, da CLT, leva ao exame do recurso denegado, o que permite o imediato julgamento do mérito do litígio.

Também em agravo de petição, que pouco se distingue do recurso ordinário, pode ter lugar o julgamento imediato do mérito. Se a impugnação à sentença de liquidação ou os embargos à execução não são examinados no mérito, porque acolhida a alegação de intempestividade, a reforma dessa decisão transfere ao tribunal o julgamento do litígio, descabendo a devolução dos autos ao juízo de primeiro grau para prolação de nova sentença.

É claro que não tem pertinência o $\S 3^{\circ}$, do art. 515 , do CPC, se o juízo do recurso entende não ser o caso de julgamento do mérito. Afirmando o tribunal a incompetência da Justiça do Trabalho para julgamento da causa, deverá aplicar o disposto no art. $113, \S 2^{\circ}$, do CPC, sendo-lhe vedado julgar o mérito do litígio ou mesmo deixar de anular a decisão recorrida. Tampouco se aplica o $\$ 3^{\circ}$ do art. 515, do CPC, se não houve extinção do processo sem exame do mérito em primeiro grau de jurisdição. Assim, se determinada Vara do Trabalho rejeita exceção de incompetência relativa, prosseguindo até decisão de mérito, reiterada a alegação no recurso, deverá o tribunal, julgando-a fundada, anular a sentença e remeter os autos à Vara do Trabalho competente.

Tampouco importa para a aplicação da regra do $\S 3^{\circ}$, do art. 515 , quando, por deficiência técnica, proclama-se a extinção do processo sem julgamento do mérito, embora se tenha examinado a pretensão deduzida. Exemplifique-se com a decisão proferida em reclamação com pedido de reconhecimento de existência de contrato de trabalho, julgada, após a completa instrução processual, extinta sem exame do mérito, porque considerado autônomo o reclamante. A conclusão sobre a natureza nãoempregatícia da relação envolve juízo de mérito. ${ }^{5 x} \mathrm{~A}$ alusão à extinção do processo

57. Em sentido diverso, partindo, segundo parece, da premissa de que o art. $515, \S 3^{\circ}$, do CPC, contrastaria com a regra do duplo grau de jurisdição, cf. Luiz Eduardo Gunther e Cristina Maria Navarro Zorning, As novas alterações do CPC e o processo do trabalho in Jornal Trabalhista, Brasília, 15 de junho de 2002 , p. $923 / 11$.

58. A propósito: "Afirmando o autor, em sua peça inaugural, a existência de uma relação empregatícia, está constituida a causa de pedir remota, substrato de todos os pleitos vindicados, sendo isso o suficiente para a fixação da competência, no plano lógico e abstrato. Admite-se, então, segundo a ótica da 
sem julgamento do mérito mostra-se, pois, equivocada. De todo modo, esse equívoco, meramente terminológico, não altera a natureza do pronunciamento, de modo que, mesmo antes da reforma introduzida pela Lei n. 10.352, em caso de reforma da sentença, ao juízo do recurso cabia desde logo examinar os pedidos deduzidos, sem devolução dos autos ao juízo recorrido. ${ }^{59}$

\section{Procedimento aplicável.}

O procedimento a observar para a aplicação do $\S 3^{\circ}$, do art. 515 , não apresenta peculiaridades significativas. Algumas poucas merecem referência.

Em primeiro lugar, não há necessidade e nem mesmo é tecnicamente correta a cisão do julgamento em diferentes sessões, uma para reforma da sentença terminativa, outra para julgamento do mérito do litígio. Na sessão designada para apreciação do recurso ordinário, considerando o relator estarem presentes os pressupostos do $\S 3^{\circ}$, do art. 515 , do CPC, apresentará de imediato pronunciamento atinente à reforma da sentença, examinando o mérito da pretensão. Acolhida sua manifestação, julgar-se-ão na mesma assentada e no mesmo acórdão todas as matérias. Não haverá um acórdão para a reforma da sentença e outro para julgamento do mérito. Nem é pertinente o adiamento da sessão, para julgamento do mérito, em outra oportunidade, do mérito. Se, no entanto, por equívoco assim se fizer, não ocorre nulidade, diante da ausência de prejuízo para as partes (CLT, art. 794).

Em segundo lugar, e como decorrência do exposto, ao impugnar o recurso interposto contra sentença terminativa, deve o recorrido desde logo oferecer suas alegações atinentes ao mérito do litígio. Não terá oportunidade subseqüente para fazêlo. Do mesmo modo, ao recorrente cabe discutir o mérito de sua pretensão. Diversamente do que ocorre no Direito português, em que o tribunal, ao reformar a sentença

reelaborada teoria abstrata do direito de ação, a veracidade provisória dos fatos constantes da exordial, relegando ao julgamento meritório a apuraçăo do juizo de certeza quanto a estes."(TRT I33 Reg., REOR n. 2074/99, Rel. Desig. Juiz Francisco de Assis Carvalho e Silva, Ac. n. 55.617, julg. em 08.09.99 in DJ de 20.04.00.

59. Assim, na Jurisprudência de Direito comuın: "Para verificar se houve exame do mérito, há que pesquisar se a pretensão formulada foi decidida. Isso tendo ocorrido, não importa que a sentença haja, equivocadamente, afirmado que o autor era carecedor da ação. Fica o tribunal, no julgamento da apelação, autorizado a examinar todas as questões pertinentes ao merecimento"(STJ - 3* T., REsp n. 31.766-0-RS, Rel. Min. Eduardo Ribeiro in DJU de 30.05.94, p. 13.480) e "É lícito ao acórdão examinar o pedido pelo mérito, se a sentença não deixou de fazê-lo, embora tenha extinto o processo sem julgamento do mérito. Inocorrência de ofensa ao art. 515 do CPC"'(STJ - $3^{3}$ T., Resp n. 7.417-SP, Rel. Min. Nilson Naves in DJU de 22.04.91, p. 4.787). 
terminativa, convida as partes "a produzir alegações sobre a questão de mérito" ${ }^{(1)}$ o regime do $\S 3^{\circ}$, do art. 515 , do CPC brasileiro não assegura o direito de manifestação em separado sobre o mérito, após a interposição do recurso. Tem o recorrido, pois, o ônus de falar, já em sua resposta ao recurso, sobre o mérito do litígio.

Sem embargo, serão votadas separadamente as questões relativas à reforma da sentença, ao cabimento do exame do mérito e, finalmente, ao próprio mérito. ${ }^{61}$ Concebe-se, pois, que, após a reforma unânime da sentença terminativa, fique vencido o relator na proposta de imediato exame do mérito, por entenderem os demais julgadores não estarem presentes os pressupostos do $\S 3^{\circ}$, do art. 515 , do CPC, caso em que haverá a baixa dos autos, para prosseguimento do processo (CPC, art. 560). Os juízes vencidos no julgamento de qualquer uma das questões deverão votar nas subsequientes, consoante o art. 561, do CPC. Ao julgador que votara pela confirmação da sentença terminativa, vencido na questão, compete pronunciar-se sobre o mérito, se assim decidir a maioria.

Outro ponto a assinalar diz respeito ao depósito recursal. O julgamento imediato do mérito prescinde de depósito recursal específico e não autoriza a posterior exigência de garantia duplicada. Por isso, se houve extinção do processo sem julgamento do mérito em relação a todos os pedidos, o recurso do reclamante chega ao tribunal sem que tenha sido feito depósito recursal algum. Reformada a sentença e julgado procedente o pedido, o recurso de revista do empregador dependerá apenas do depósito do valor limite previsto em lei para este último recurso, não cabendo a exigência cumulada do valor exigido também para a interposição do recurso ordinário.

12. Impugnação do pronunciamento sobre a aplicação do $\S 3^{\circ}$, do art. 515 , do CPC.

A aplicação ou não da regra do $\S 3^{\circ}$, do art. 515, do CPC, não envolvendo mera faculdade do juízo do recurso ${ }^{62}$ sujeita-se, em tese, a impugnação. O recurso apropriado para tanto é, no caso de decisão proferida por Tribunal Regional, a revista, prevista no art. 896, da CLT. Não incide o óbice previsto no Enunciado 126, do Tribunal Superior do Trabalho, até porque a discussão sobre a necessidade ou não de novas

60. Código de Processo Civil português, art. 753, n. 2.

61. Sobre o tema, amplamente, José Carlos Barbosa Moreira, Comentários ao Código de Processo Civil cit., n. 372 , p. 663 e ss.

62. Antes, item 8. 
provas não envolve reexame de fatos, mas aplicação de normas legais sobre direito probatório ${ }^{6.3}$

Nem sempre, porém, o recurso de revista poderá ser oferecido. Se o tribunal nega a aplicação do $\S 3^{\circ}$ do art. 515 , do CPC, determinando o retorno dos autos ao juízo de primeiro grau, qualquer que seja o motivo, seu pronunciamento revestese de caráter interlocutório e não comporta imediata impugnação por meio de recurso, como decorrência do disposto no art. 893, $\S 1^{\circ}$, da CLT, e Enunciado 214, do Tribunal Supcrior do Trabalho ${ }^{64}$ Eventual equívoco scrá reparado posteriormente.

Determinando o tribunal o retorno dos autos ao juízo de primeiro grau, após reformar sentença terminativa, sem examinar a possibilidade de aplicação do $\$ 3^{\circ}$, do art. 515, do CPC, tem-se por configurada omissão. Admite-se, na hipótese, a apresentação de embargos de declaração (CPC, art. 535, inciso II), os quais poderão revestir-se de efeito modificativo (Enunciado 278, do Tribunal Superior do Trabalho, combinado com Orientação Jurisprudencial n. 142, da, Subseção de Dissídios Individuais do Tribunal Superior do Trabalho) e, em consequiência, propiciar a continuação do julgamento já no tribunal, independentemente da prolação de nova sentença.

63. Em sentido contrário, sem razão, todavia: "A verificação da necessidade ou não de outras provas para alicerçar o julgamento da causa deınandaria...o reexame das provas dos autos, vedado nesta Instância Especial, a teor do Verbete Suınular n. 7-STJ"(STJ - 4ª T., REsp n. 210.607-RJ, Rel. Min. Sálvio de Figueiredo in Revista do Superior Tribunal de Justiça, junho de 2002, vol. 154, p. 393). A mesına diretriz prevalece no Supremo Tribunal de Justiça de Portugal, como mostra o seguinte acórdāo: "A suficiência ou insuficiência de factos para julgar de mérito no despacho saneador e a apreciação das provas integram, em princípio, questão de facto da exclusiva competência das instâncias."(STJ - Processo n. 1.527, Rel. Correias de Paiva, julg. em 16.01.87).

64. De acordo com isso, em situação assemelhada: "Vl "h.3\#h3" V "h5\#h5" Recurso de VI "h4\#h4" V "h6\#h6" revista - Descabimento. Acórdão regional que ordena o retorno dos autos ao primeiro grau de jurisdição, para providências, sem julgamento definitivo da causa. Irrecorribilidade. A teor do En. $n^{\circ} 214$ do TST, "as decisões V "h5\#h5" IV "h7\#h7" interlocutórias, na Justiça do Trabalho, só são recorríveis de imediato quando terminativas do feito, podendo ser impugnadas na oportunidade da interposição de V "h6\#h6" V "h8\#h8" recurso contra a $\backslash$ " "h7\#h7" V| "h9\#h9" decisão definitiva, salvo quando proferidas em acórdāo sujeito a ll "h8\#h8" o mesmo tribunal". Tal verbete espelha o comando do art. 893, $\$ 1^{\circ}$, da CLT, no sentido de que "os incidentes do processo são resolvidos pelo próprio Juízo ou Tribunal, adınitindo-se a apreciação Jo merecimento das decisões hI0V "h9\#h9" VI "hlI\#hl|" interlocutórias somente em V "hl0\#hlo" II

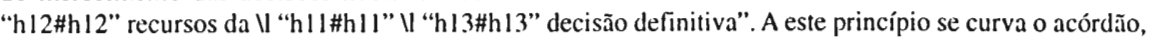
que, decidindo questões preliminares ou prejudiciais, devolve os autos ao primeiro grau de jurisdição, para prosseguir no julgamento ou adotar providências, que adiem o provimento regional definitivo para uın segundo momento. Tal V "h12\#hl2" VI "hl4\#hl4" decisão, por teratológica que possa ser, não desafiará VI

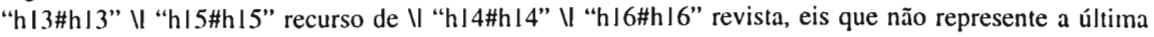
manifestação jurisdicional, em grau ordinário. Tem-se, aqui, salutar expressão de celeridade processual, enquanto se evita o percurso desnecessário dos autos entre as instâncias recursais. II "h $15 \#$ \#15" VI "h 17\#h 17" Recurso de VI "h|6\#h|6" II "h] 8\#hl8" revista não conhecido."(TST - 2 T., RR n. 372.244, Rel. Juiz Convocado Alberto Luiz Bresciani Pereira, julg. em 14.02.01 in DJU de 16.03.01, p. 737). 


\section{Direito intertemporal.}

A afirmação, tão freqüente, de que as normas de Direito Processual têm aplicação imediata, apanhando os processos $\mathrm{cm}$ curso, ${ }^{0.5}$ ć, em sua generalidade, excessiva. Nem sempre há como compatibilizar os atos já praticados com as novas disposições legais, como se pôde verificar com o procedimento sumaríssimo previsto no Código de Processo Civil de $1973^{66}$ e, mais recentemente, com o procedimento criado pela Lei n. $9.957 .^{67}$

No caso da Lei n. 10.352 a aplicação da regra do $\S 3^{\circ}$ do art. 515, do $\mathrm{CPC}$, aos recursos interpostos antes de sua vigência, embora julgados posteriormente, comprometeria o contraditório, na medida em que o recorrido, dispensado, pela regulamentação anterior, de discutir o mérito do litígio em sua resposta ao recurso, poderia ser surpreendido pela decisão do tribunal.

O critério mais adequada para a solução do conflito de leis no tempo em matéria recursal corresponde à observância da norma vigente quando da prolação da sentença. $O$ direito ao recurso surge com o julgamento, segundo bem assentado em doutrina $^{68}$ regendo-se, pois, pelas regras então vigentes. Alterações posteriores não repercutem, em regra, sobre a posição processual da parte. Nem mesmo a aplicação da lei vigente ao tempo da publicação da decisão recorrida - critério que antes se propusera $^{69}$ e que conta com amplo apoio da doutrina ${ }^{70}$ e da jurisprudência ${ }^{71}$ - é correto.

65. Por todos, Paul Roubier, Le droit transitoire, Paris, Dalloz, 1960, n. 101, p. 545.

66. A propósito, decidiu o Supreıno Tribunal Federal: "Procedimento sumaríssimo. Este ganha feição própria a partir da petição inicial (CPC, art. 276). Esta sua configuração, que surge, portanto, da proposilura da açĩo, impede que, iniciada a demanda pelo procedimento ordinário e alé contestada, lal ainda na vigência da antiga lé adjetiva civil, venha, quando em grau de recurso, e aí já vigorando o novo Código, ser aplicado o prazo de 5 dias do parágrafo único do art. 508. Recurso extraordinário conhecido c provido."(STF - Ia T., RE n. 82.357/PR, Rel. Min. Bilac Pinto, julg. em 04.11.75 in DJU de 26.12.75 e RTJ v. 76, p. 653).

67Cf. TST - 2a T., AIRR n; 698.747/00, Rel. Min. José Luciano de Castilho Pereira, julg. em 21.02.01 in DJU de 23.03.01, p. 608; TST - 5a T., AIRR n. 717.985/00, Rel. Min. Joāo Batista Brito Pereira, julg. em 09.05.01 in DJU de 24.05.01, p. 731 e TST - 4a T., RR n. 715.592/00, Rel. Juiz Convocado Renato de Lacerda Paiva, julg. em 06.06.01 in DJU de 29.06.01, p. 837.

68. Cf., a propósito, Galeno de Lacerda, O novo direito processual e os feitos pendentes, Rio de Janeiro, Forense, 1974, p. 70, e Athos de Gusmão Carneiro, Lei nova e admissibilidade de recursos in Revista de Processo, São Paulo, RT, vol. 108, p. 213 e segs.

69. Estêvão Mallet, Reforma de sentença terminativa e julgamento imediato do mérito no processo do trabalho in Revista da AMATRA II, São Paulo, n. 7, p. 16 e segs.

70. José Manoel de Arruda Alvim, Curso de direito processual civil, São Paulo, RT, vol. I, n. 13.

71. "Segundo princípio de direito intertemporal, o recurso se rege pela lei vigente à data em que 
Apresenta falhas e inconvenientes, na medida em que pode fazer com que decisões proferidas na mesma data fiquem, sem qualquer razão relevante, sujeitas a normas legais diversas somente porque publicadas em diferentes momentos, por conta de diversa tramitação burocrática dos processos. ${ }^{72}$

Em síntese, o $\$ 3^{\circ}$, do art. 515, do CPC, aplica-se desde logo aos recursos interpostos contra decisões prolatadas após o início da vigência da Lei n. 10.352, não importando o momento em que ajuizada a ação, encerrada a instrução ou publicada a sentença. Os recursos interpostos contra decisões prolatadas anteriormente, porém, ficam ainda sujeitos ao regime do direito anterior, mesmo quando julgados já sob a vigência das disposições da Lei n. 10.352.

São Paulo, junho de 2003.

publicada a decisão..."(STJ - 4² T., RMS n. 38-SP, Rel. Min. Sálvio de Figueiredo in DJU de 04.06.90, p. 5.061) e "É entendimento pacífico nesta Corte que a lei vigente à data da publicação da sentença é a que rege a interposição de recursos"(STJ - $5^{2}$ T., AgRgAgRgAI n. 391 .043-RJ, Rel. Min. Felxi Fischer in Bol. AASP n. 2297/649). A Súmula n. I, do Tribunal Regional Federal da I" Região tem o seguinte teor: "A lei regente do recurso é a em vigor na data da publicação da sentença ou decisão."

72. Alhos de Gusmão Carneiro, Lei nova e admissibilidade de recursos cit., p. 219. 